\title{
Thermal Lifetime Evaluation of Electrical Machines Using Neural Network
}

\author{
G. Turabee ${ }^{+}$, M. Raza Khowja*, V. Madonna*, P. Giangrande*, G. Vakil , C. Gerada*, M. Galea* \\ ${ }^{*}$ Power Electronics, Machines and Control (PEMC) Group, University of Nottingham, UK \\ ${ }^{+}$School of Science and Technology, Nottingham Trent University, UK \\ Email: Gulrukh.Turabee@gmail.com, Raza.Khowja@Nottingham.ac.uk
}

\begin{abstract}
This paper proposes a surrogate approach which utilises an supervised neural network to significantly shorten the time required for thermal qualification of electrical machines' insulation. The proposed approach is based on a feedforward neural network trained with Bayesian Regularization BackPropagation (BRP) algorithm. The network predicts the winding's insulation resistance trend with respect to its thermal aging time. The predicted insulation resistance is evaluated against experimental measurements and an excellent match is found. Its trend is used for estimating the sample's time to failure under thermal stress at various temperatures. The temperature index of the insulating material, predicted by the neural network, matches with an error of just $0.4 \%$ margin against the experimental findings.
\end{abstract}

Index Terms - Aging time, Neural network, accelerated lifetime test, thermal life of insulation, and Insulation Resistance.

\section{INTRODUCTION}

$\mathbf{T}$ HE thermal lifetime evaluation of an insulation system is a procedure aiming at extrapolating its thermal endurance characteristic i.e. the expected lifetime with respect to the applied stress (temperature of the insulating material). Such evaluation is conventionally based on accelerated lifetime tests, which consist in stressing the insulation at higher temperatures than those experienced during normal operating conditions, with the aim of tuning a lifetime prediction model [1-4].

Different stresses such as ambient, electrical, thermal and mechanical stress can shorten the life of insulation systems in electrical machine. Thermal stress among all is a primary source of gradual insulation deterioration resulting in eventual winding failure. Hence, the need to evaluate a winding insulation system for its capability in maintaining the dielectric properties under thermal aging $[5,6]$. Based on the Arrhenius law, Insulation lifetime models are suitable for evaluating the lifetime consumption of electrical machines operating with continuous-duty cycle, where the winding temperature is remains consistent throughout the working operation. Arrhenius law states that the insulation lifetime reduces by half for every $8-10^{\circ} \mathrm{C}$ increase in temperature [7-10]. In terms of insulation, the weakest link is generally denoted by the winding turn-to-turn enamel layer [11]. The faults in the electrical machines, related to the insulation, are mostly orginated with by a inter-turn insulation failure that results in over-temperaturesn[12]. This triggers the most severe failures and eventually lead to the machine outage. To avoid this condition, an accurate thermal lifetime evaluation of the insulation system required [13]. The paper proposes a novel method for the thermal lifetime evaluation of electrical insulation systems, in order to reduce the experimental test time of the thermal aging which are traditionally based on the regression method [14-16]. This task has been performed using supervised feedforward neural network trained with Bayesian Regularization Back-Propagation (BRP) algorithm [17]. The results predicted using BRP are then tested and compared with the experimental results in order to validate the efficiency of the new methodology. The paper is arranged as follows: section II presents an overview of test setup and procedure for lifetime evaluation. In section III, the theoretical background of the adopted neural network is presented. In section IV, considerations on the diagnostic parameters and the breakdown criterion are discussed. The predicted results, obtained from BRP are presented in section V, followed by the thermal lifetime modelling in section VI. Lastly, section VII concludes the paper.

\section{MEASUREMENT TeSt SETUP}

\section{A. Test Sample}

A twisted pair enameled wire with thermal class of $220^{\circ} \mathrm{C}$ and a bare copper diameter of $0.4 \mathrm{~mm}$ is used a test sample as shown in Fig 1a. The wire is insulated using a double enamel layer of $25 \mu \mathrm{m}$, namely a modified-polyester as base coat which is overcoated with polyamide-imide. The length of the sample wire is $200 \mathrm{~mm}$ with 20 twists on it, whose insulation characterization is required ASTM standards D2307 has been followed for choosen sample's arrangement [14]. Such wire topology is commonly employed for the windings of low voltage $(<1000 \mathrm{~V})$ rotating machines $[18,19]$.

\section{B. Test Procedure}

Accelerated aging test are performed for test procedures which are generally used for thermal qualification of electrical machines in which the samples are thermally aged with stresses above the insulation thermal class. According to the technical standard ASTM D2307, 10 twisted pair samples need to be used for each aging temperature. The aging process was carried out, in a controlled oven (Fig. 1b), at the aging temperature $290^{\circ} \mathrm{C}$ with an aging cycle of 8 hours (or $8 \mathrm{~h}$ ). In other words, after every $8 \mathrm{~h}$ of thermal exposure, the samples were cooled down to ambient temperature and their dielectric properties were assessed. Parameters such as insulation capacitance (IC), dissipation factor, (Tan $\delta$ ), and insulation resistance (IR) were measured using a MEGGER Delta 4000 


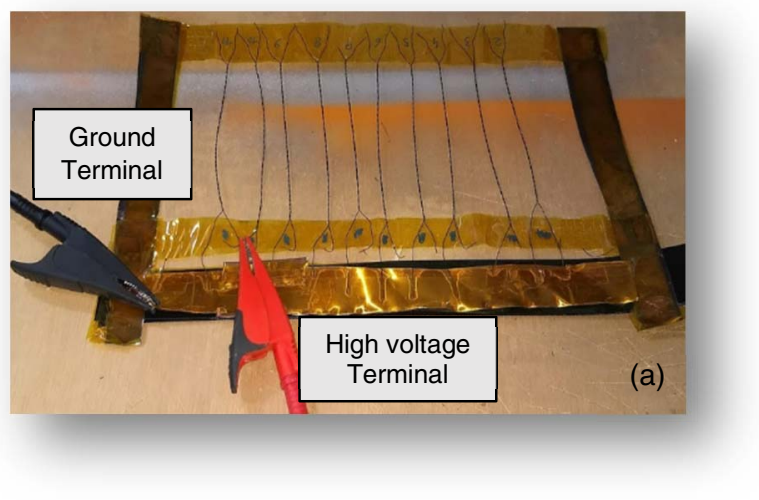

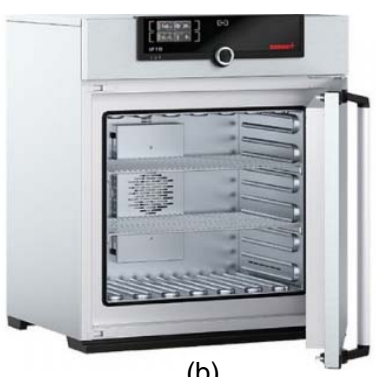

(b)

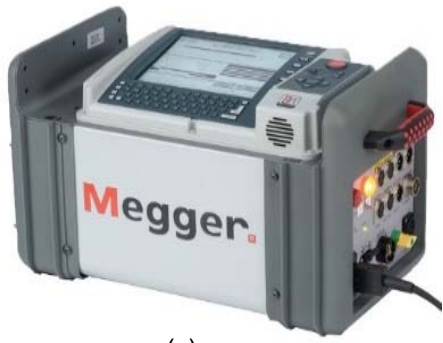

(c)
Fig. 1. Measurement Setup (a) Specimen's Holder in an unaged condition (b) MEMMERT UF260 Oven (c) Diagnostic Device MEGGER 4000

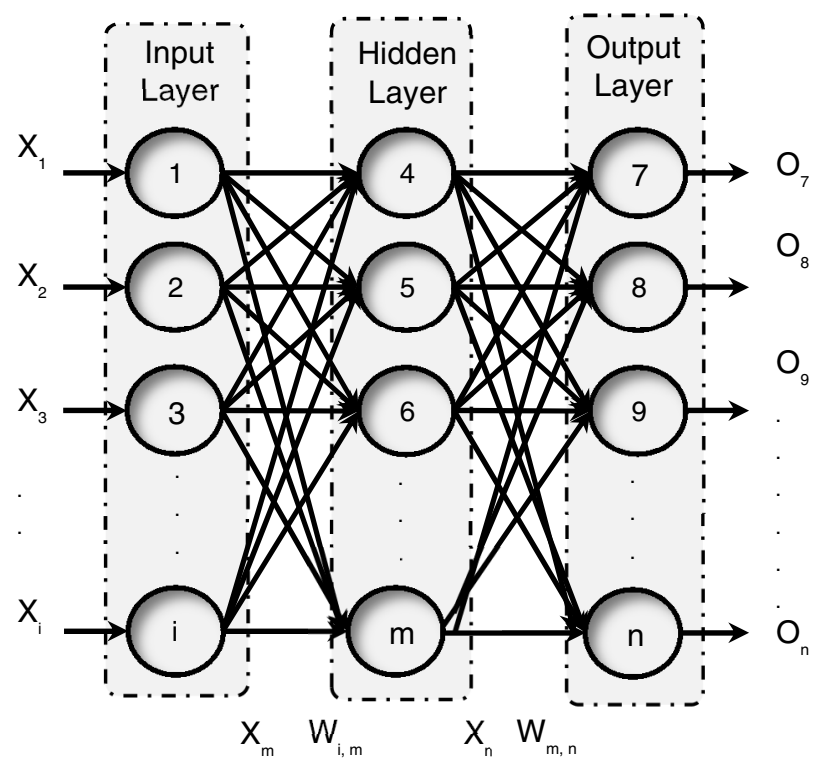

Fig. 2. Architecture of BP Neural Network

as shown in Fig. 1c. Throughout the aging procedure, the samples are also subject to the AC hipot test, used for, eventually, detecting the insulation breakdown. Such test consists in assessing the wire's dielectric withstand capability when a voltage from 0 to $500 \mathrm{~V}$ is applied across the insulation layer, in step of $50 \mathrm{~V}$. In case a sample fails the AC hipot test, the time-to-failure is recorded. The aging procedure was carried out until the insulation breakdown is detected on all the considered samples [20].

\section{NEURAL NETWORK}

A feedforward neural network is used, that was trained with Bayesian Regularization Back-Propagation algorithm, to predict the diagnostic properties of the samples. The algorithm selection was based on a trade-off study among 4 neural networks, the details of which can be found in [2].

\section{A. Theoretical Background}

A BP neural network is a one-way multi-layer forward network as shown in Fig. 2. The network comprises of one input and output node, with one more hidden nodes implied, with no coupling between the nodes in the same layer. Transmission of input signals takes places from input layer in turn through the hidden layer nodes, and reaches the final output nodes at the last. Hence, the output of next layer is only influenced by the nodes of previous layer [22, 23]. Having advantage of a reliability and simple structure, this neural network is an outstanding tool for modelling of complex systems. When a certain pattern is fed in the input layer, the weighted sum $W$ of the input $X$ to the $j^{\text {th }}$ node is represented by Equation (1) in the hidden layer calculating combined input to neuron. The weighted value from a bias node is represented by $\theta$ with an output value of 1 .

$$
\mathrm{S}_{m}=\sum_{i=1}^{n} W_{i, m} X_{j m}+\theta
$$

Action potential of neuron is decided by an appropriate activation function (i.e. sigmoid function as shown in (2). The output value from activation function estimates the neuron's output and is an input value for the neurons in the successive layer connected to it.

$$
O_{m}=X_{n}=\frac{1}{1+e^{-S_{m}}}
$$

Considering the predicted activation value of the output node, $n$, is $O_{n}$ and the targeted value is $t_{n}$, then the difference between them can be calculated as given by (3).

$$
\Delta_{n}=t_{n}-O_{n}
$$

(7) is used to alter the weight, $W_{m, n}$, between the node $\mathrm{m}$ and output node, $\mathrm{n}$, where $\Delta W_{m, n}$ is the variation in the weight between nodes $m$ and $n$ and $l_{r}$ indicated learning rate.

$$
\Delta W_{m, n}=l_{r} X_{n} \Omega_{n}
$$

$\Omega_{n}$ is the error signal for node in the output layer and can be represented by (8).

$$
\Omega_{n}=\Delta_{n} O_{n}\left(1-O_{n}\right)
$$

\section{B. Network Training}

To train the BRP network, the Bayesian regularization algorithm is used. In this case, the training is carried out on a 

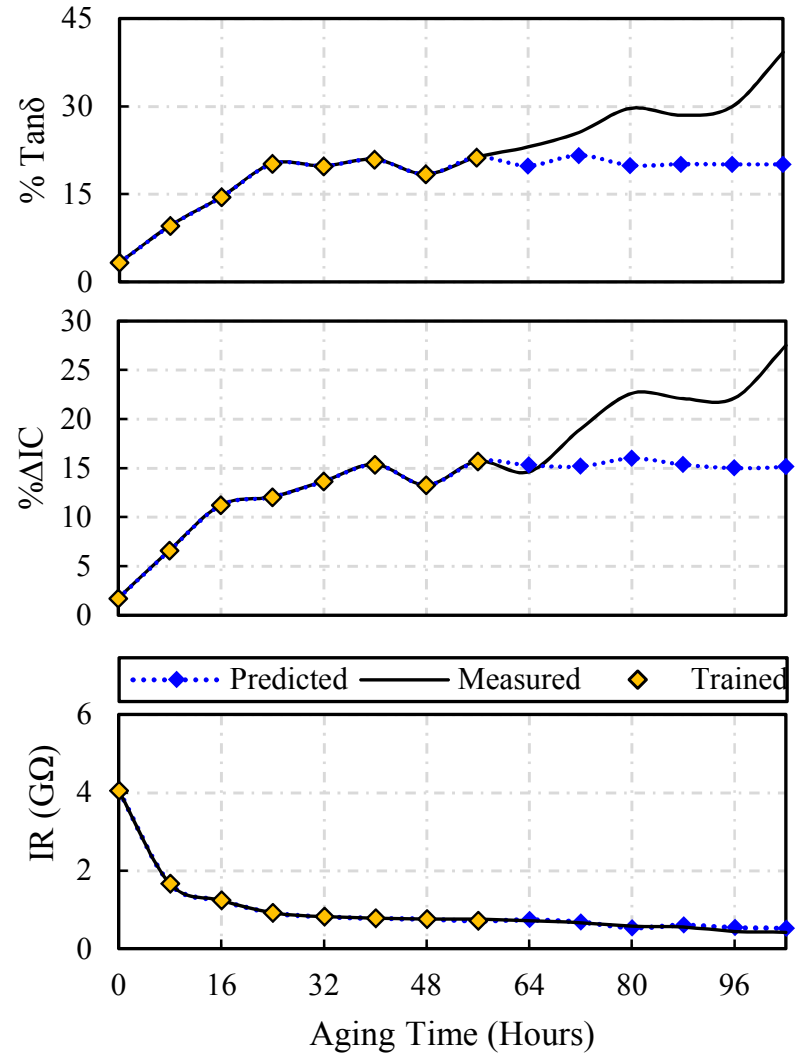

Fig. 3. Selection of Diagnostic Parameter for Prediction Purpose

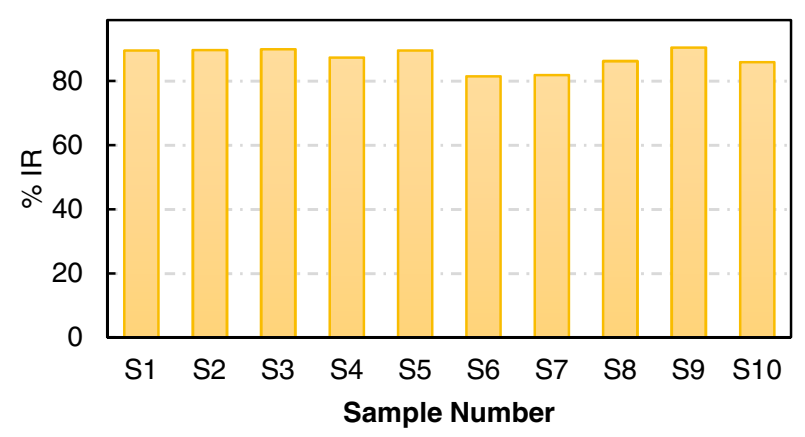

Fig. 4. \%IR of each sample at $290^{\circ} \mathrm{C}$ themal exposure

given set of samples having the form $(\mathrm{Ri}+\mathrm{Ri}+1)$, where $\mathrm{Ri}$ indicates the insulation resistance value at aging time ti whereas, $\mathrm{Ri}+1$ is the future or predicted value of the insulation resistance at $\mathrm{i}+1$.

\section{Prediction Approach}

For every sample, the future value of diagnostic parameter $\mathrm{R}_{\mathrm{i}+1}(\mathrm{i}=1,2,3,4 \ldots \mathrm{n})$ can be predicted at a particular aging time $t_{i+1}$ by performing the training on a set of data having the input parameter aging time as $\left(\mathrm{t}_{\mathrm{i}}, \mathrm{t}_{\mathrm{i}+1}\right)$ and output parameter as insulation resistance $\left(I R_{i}, I R_{i+1}\right)$. The training is repeated from the beginning for each sample. To improve the prediction results, the first value is omitted from the dataset each time a future value is predicted. In this way, the network can be fed with an equal number of data points throughout and the algorithm was trained on the latest target value which helped in the prediction of more accurate future values. With the dataset containing $I_{i} \ldots I R_{n}$, the network was trained until $7^{\text {th }}$ aging cycle (i.e. $8^{\text {th }}$ value or $56 \mathrm{~h}$ learning time) to predict the future value $I_{\mathrm{i}+1}$ (i.e. $9^{\text {th }}$ value). However, in order to get the $R_{i+2}\left(10^{\text {th }}\right.$ value $)$, the latest predicted value $R_{i+1}\left(9^{\text {th }}\right.$ value $)$ was included in the dataset $\left(\mathrm{IR}_{\mathrm{i}} \ldots \mathrm{IR}_{\mathrm{i}+1}\right)$. The first value of the dataset was omitted simultaneuously when each future value was predicted.

\section{SELECTION CONSIDERATIONS}

\section{A. Selection of Diagnostic Parameter for Prediction}

Using the device called "MEGGER Delta 4000", diagnostic parameters such as , IC,Tan $\delta$ and IR were measured for a random sample (i.e. S1) aged at $290^{\circ} \mathrm{C}$. Fig. 3 illustrates the predictive results of differential IC $(\Delta \mathrm{IC})$, Tan $\delta$ and IR using BRP neural network. The $\triangle \mathrm{IC}$ is estimated using (6), where $\mathrm{IC}_{500}$ is the IC measured at $500 \mathrm{~V}$ and $\mathrm{IC}_{100}$ is the IC measured at $100 \mathrm{~V}[3,4]$. As can be seen in Fig. 3 the prediction results, using neural network, gives the closest match for IR against the measured data as opposed to other diagnostic parameters. Therefore, the "IR" is selected as diagnostic parameter for prediction purpose i.e. to predict and build the lifetime model of insulating material.

$$
\% \Delta I C=100 \times \frac{I C_{500}-I C_{100}}{I C_{500}}
$$

\section{B. Breakdown Criterion}

The breakdown criterion was made, at $290^{\circ} \mathrm{C}$ thermal exposure, using time-to-failure of each sample. Fig. 4 shows $\%$ IR of all the samples that was caculated with respect to its unaged IR value by using (7), where, $I_{\text {zero }}$ is the unaged value

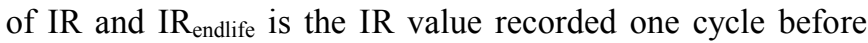
insulation breakdown had occurred, at $500 \mathrm{~V}$ applied voltage. The \%IR corresponding to the sample's mean time-to-failure is equal to $87.22 \%$ (using (8)) and therefore chosen as insulation's breakdown criterion which will be used, to predict the time-to-failure, for thermal exposures other than $290^{\circ} \mathrm{C}$.

$$
\begin{gathered}
\% I R=100 \times \frac{I R_{\text {zero }}-I R_{\text {endlife }}}{I R_{\text {zero }}} \\
I R_{\text {breakdown }}=\frac{1}{N} \sum_{k=1}^{n} \% I R
\end{gathered}
$$

\section{RESUlTS \& DiSCUSSIONS}

For prediction analysis, the test procedure was started and completed at maximum thermal exposure (i.e. $290^{\circ} \mathrm{C}$ ) until a breakdown in every test sample was perceived, in order to set a breakdown criterion for other thermal exposures. The test procedure continued for $250^{\circ} \mathrm{C}$ and $270^{\circ} \mathrm{C}$ aging temperatures until the $7^{\text {th }}$ aging cycle, where, the test procedure was intentionally ceased to predict the life of each sample using neural network approach. Once the prediction phase was 

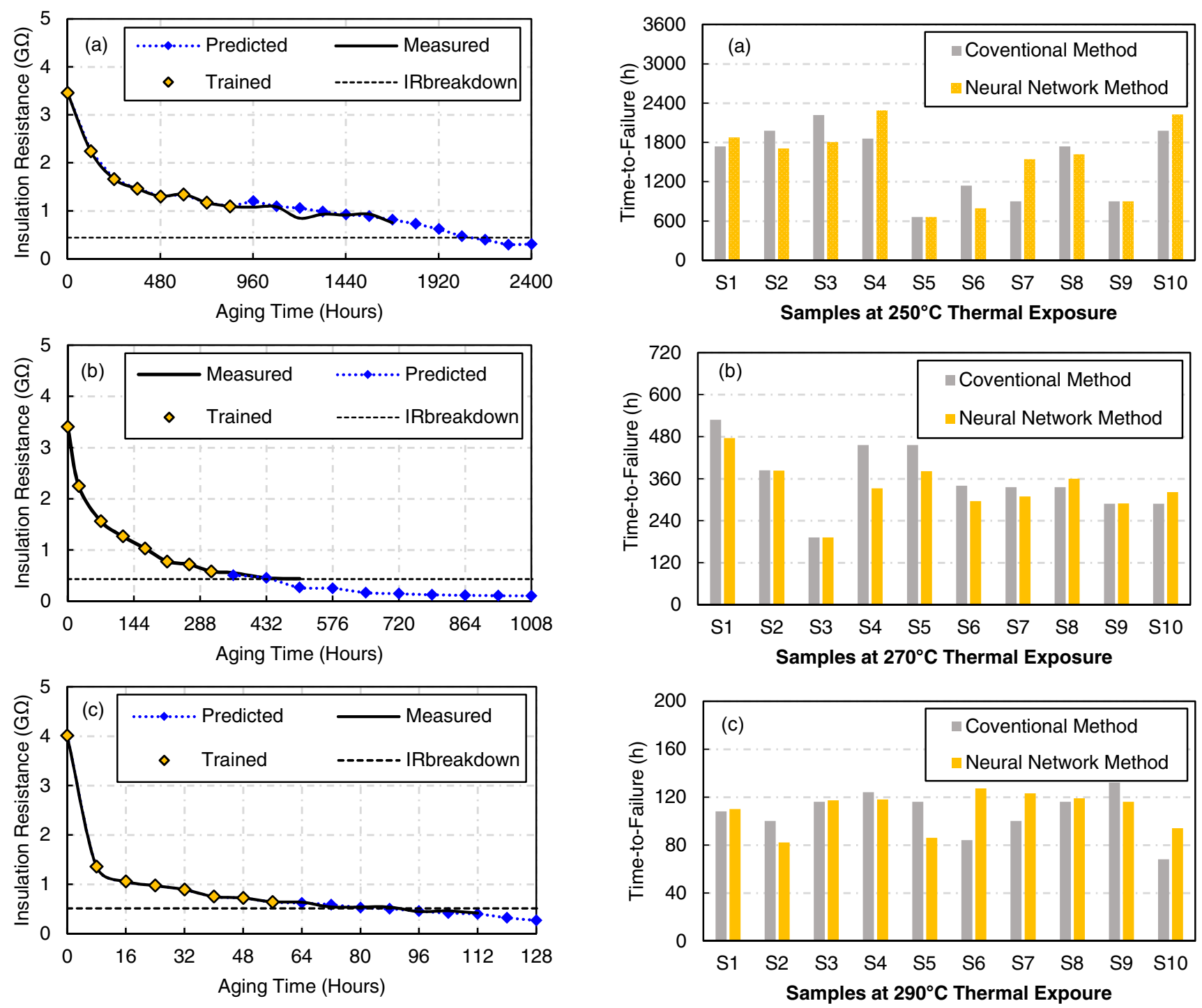

Fig. 5. IR Prediction Results (a) at $250^{\circ} \mathrm{C}$ thermal exposure, $\mathrm{S} 10$ (b) at $270^{\circ} \mathrm{C}$ thermal exposure, $\mathrm{S} 1$ (c) at $290^{\circ} \mathrm{C}$ thermal exposure, S5

completed, the test procedure was resumed and completed for valdiation purpose. The IR of every sample was predicted using the methodology discussed in the preceding section. The BP network was trained until the $7^{\text {th }}$ aging cycle (i.e. total 8 data points including unaged value) and the samples whose failure was detected before the $7^{\text {th }}$ aging cycle were discarded and hence, not included in the prediction analysis. To estimate the time-to-failure of each sample at various thermal exposures, the BP network was designed to predict the IR values for longer time span (i.e. $2400 \mathrm{~h}, 1008 \mathrm{~h}$ for thermal exposures of $250^{\circ} \mathrm{C}$ and $270^{\circ} \mathrm{C}$ respectively). A limited number of thermal aging cycles were experimentally carried out on two sets of 10 samples each, at thermal exposures of $250^{\circ} \mathrm{C}$ and $270^{\circ} \mathrm{C}$. The recorded IR values were used for training the neural network, with the aim of predicting the samples' insulation breakdown, without actually carrying-out the tests until all samples were "dead". It is worth recalling that a sample is considered as "dead" when a \%IR variation of

Fig. 6. Time-to-Failure (a) at $250^{\circ} \mathrm{C}$ thermal exposure (b) at $270^{\circ} \mathrm{C}$ thermal exposure(c) at $290^{\circ} \mathrm{C}$ thermal exposure

$87.22 \%$, with respect to its unaged value, is reached. Fig. 5a to Fig. $5 \mathrm{c}$ shows the results of the predicted IR trend for one sample aged at $250^{\circ} \mathrm{C}, 270^{\circ} \mathrm{C}$ and $290^{\circ} \mathrm{C}$ respectively. As clearly visible in Fig. 5, the neural network results are essentially able to match the experimental measurements, providing an excellent IR estimation. At this point, it is possible to employ the network's prediction to estimate the time-to-failure of all 30 samples at three thermal exposures, which are reported in Fig. 6a to Fig. 6c.

\section{THERMAL LIFETIME MODEL}

For a constant mode of operation, insulating material used in electrical machines is characterised by a constant winding temperature throughout their working operation [24]. In this case, for low voltage electrical machines, thermal stress is the most recognised aging factor that gradually deteriorates the insulation's lifetime. Therefore, a thermal lifetime model, based on the Arrhenius Law, is developed in this section. According 

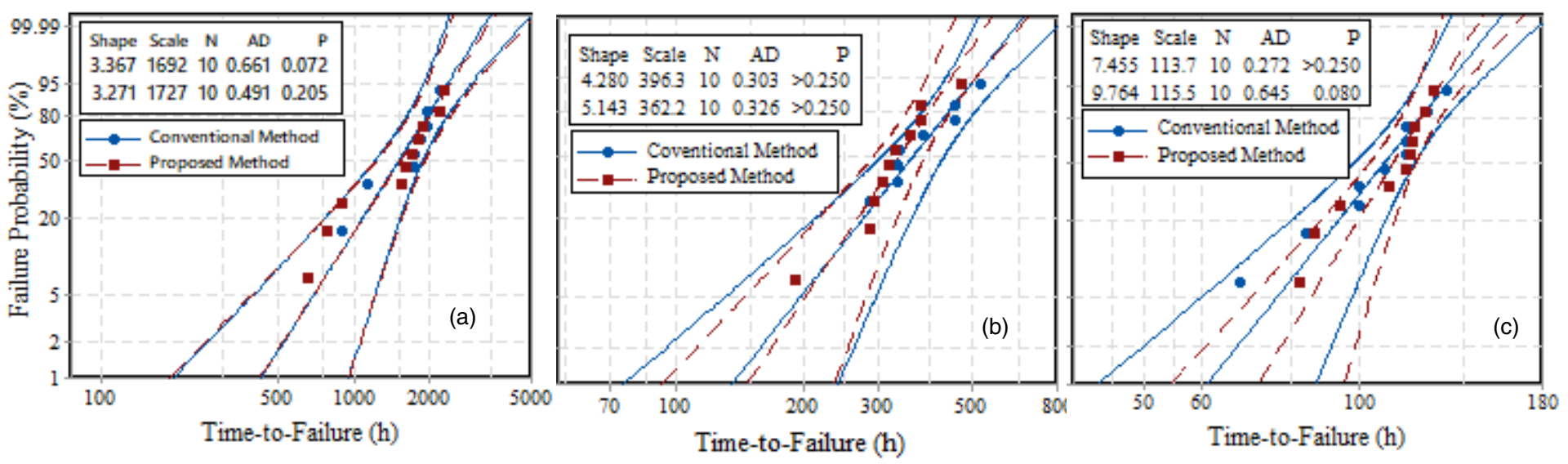

Fig. 7. Weibull Probability Plot (a) $250^{\circ} \mathrm{C}$ Themal Exposure (b) $270^{\circ} \mathrm{C}$ Themal Exposure (c) $290^{\circ} \mathrm{C}$ Themal Exposure

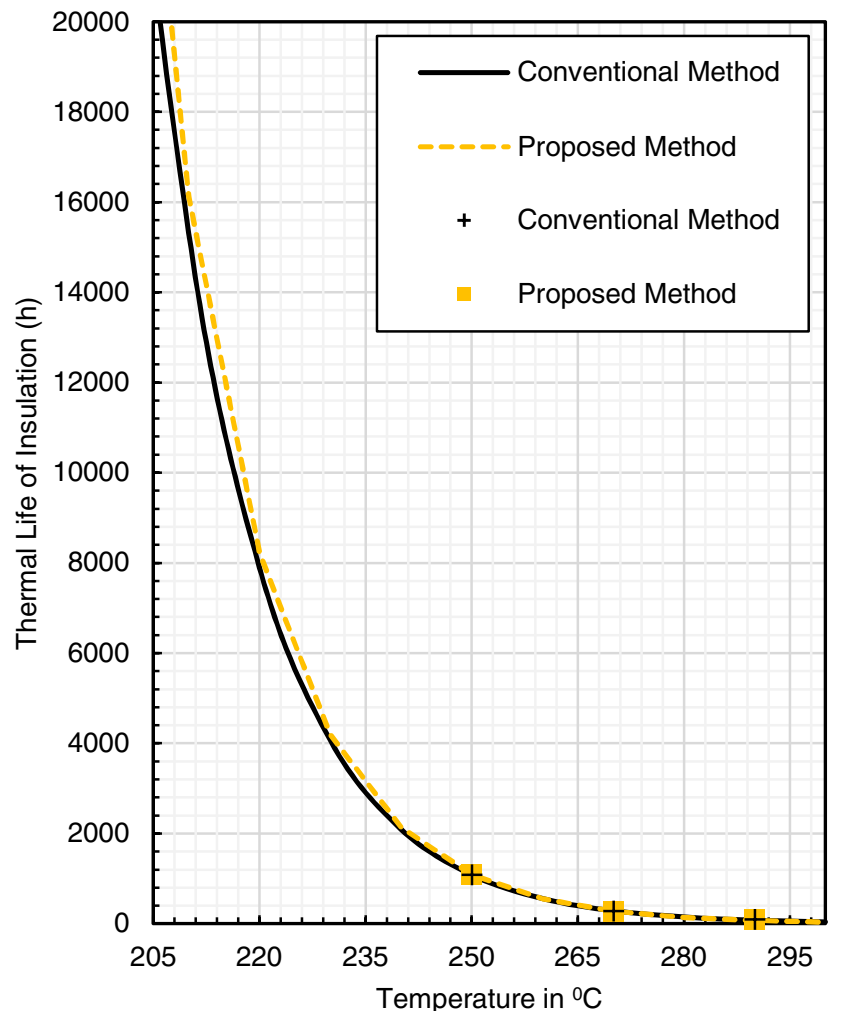

Fig. 8. Comparison of Insulation Life vs Temperature Charateristic on Linear Graph

to the Arrhenius law [8], the thermal life of a solid insulating material is given by (9)

$$
L=A e^{B / T}
$$

where, $\mathrm{A}$ and $\mathrm{B}$ are material constants, whilst, $\mathrm{L}$ is the thermal life of inuslating material in hours at operating temperature $\mathrm{T}$ in Kelvin. Using the time-to-failures of Fig. 6, the Weibull Probability Distribution, with a $95 \%$ confidence interval, is plotted at all three thermal exposures(Fig. 7). In order to predict the temperature index of the insulating material, using

\begin{tabular}{cccc}
\multicolumn{4}{c}{ COMPARISON OF 20\% CUMULATIVE PROBABILITY FAILURES } \\
\hline AGING TEMPERATURE & $\mathbf{2 5 0}^{\mathbf{}} \mathbf{C}$ & $\mathbf{2 7 0}^{\circ} \mathbf{C}$ & $\mathbf{2 9 0}^{\mathbf{}} \mathbf{C}$ \\
\hline Conventional Method & 1084.1 & 279.1 & 92.9 \\
Proposed Method & 1092.0 & 270.6 & 99.0 \\
Relative Error (\%) & -0.73 & 3.05 & -6.57 \\
\hline
\end{tabular}

TABLE II

MATERIAL CONSTANTS AND TEMPERATURE INDEXES

\begin{tabular}{ccccc}
\hline PARAMETERS & A & B & T.I $\left({ }^{\circ} \mathbf{C}\right)$ & R \\
\hline Conventional Method & $1.691 \mathrm{e} 10$ & -0.06626 & 205.97 & 0.9988 \\
Proposed Method & $2.218 \mathrm{e} 10$ & -0.06731 & 206.79 & 0.9986 \\
\hline
\end{tabular}

both conventional and proposed method, the inuslation lifetime corresponding to the $20 \%$ cumulative probability failures are extracted for all three thermal exposures which are illustrated in Table I. It should be noted that the lifetime models can be made with different failure percentile, depending on the reliability requirement of the specific applications [25]. From Table I, it can be seen that the lifetime of the insulation, predicted by the BP network, is consistent with the one obtained from the experimental test procedure. From the attained results, the higest error is $-6.57 \%$ in the case of $290^{\circ} \mathrm{C}$ thermal exposure, whereas, the minimum error of $0.73 \%$ is achieved at $250^{\circ} \mathrm{C}$ thermal exposure which shows the effectiveness of the proposed method, in terms of shortening the test procedure of lifetime evaluation of insulating material. Once the samples' lifetime corresponding to the chosen reliability requirement is obtained from Weibull Distribution, the thermal life of insulating material is extrapolated, by using MATLAB curve fit exponential tool, to a lifetime of 20,000 hours (i.e. standard lifetime required for electrical machines), whose constants A and B are listed in Table II, for both conventional and proposed methods of lifetime evaluation. As can be observed from Table II, the proposed approach is actually able to predict the temperature index of the material which has made an excellent agreement, giving the percentage error of just $0.40 \%$ when compared to a conventional method of lifetime evaluation. Hence, by adopting the proposed approach, a significant amount of testing time can be saved since the thermal exposures do not need to be performed until the insulation breakdown is detected. 


\section{CONCLUSIONS}

Fast and accurate tool is developed in this paper, using the neural network approach, to predict the lifetime of insulating material used in electrical machines. The proposed approach employes a supervised neural network that significantly shortens the time required, in accelerated aging tests, for the thermal qualification of electrical machines' insulation. It predicts the trend of insulation resistance with respect to its aging time. The breakdown criterion was defined to evaluate the time-to-failure of each sample which was then used to build the thermal lifetime model of the insulation corresponding to $20 \%$ cumulative probability failures. The temperature index was determined through both conventional and proposed approaches and an excellent agreement was found, with an error of just $0.4 \%$.

\section{REFERENCES}

[1] G. C. Stone, E. A. Boulter, I. Culbert, and H. Dhirani, Electrical insulation for rotating machines: design, evaluation, aging, testing, and repair. John Wiley \& Sons, 2004.

[2] G. Turabee et al., "The Role of Neural Networks in Predicting the Thermal Life of Electrical Machines," IEEE Access, vol. 8, pp. 40283 40297, 2020.

[3] V. Madonna, P. Giangrande, G. Migliazza, G. Buticchi, and M. Galea, "On the Thermal Insulation Qualification of Low Voltage Electrical Machines," in IECON 2019-45th Annual Conference of the IEEE Industrial Electronics Society, 2019: IEEE.

[4] V. Madonna, P. Giangrande, G. Migliazza, G. Buticchi, and M. Galea, "A Time-Saving Approach for the Thermal Lifetime Evaluation of Low Voltage Electrical Machines," IEEE Transactions on Industrial Electronics, pp. 1-1, 2019.

[5] V. Madonna, P. Giangrande, L. Lusuardi, A. Cavallini, and M. Galea, "Impact of thermal overload on the insulation aging in short duty cycle motors for aerospace," in 2018 IEEE International Conference on Electrical Systems for Aircraft, Railway, Ship Propulsion and Road Vehicles \& International Transportation Electrification Conference (ESARS-ITEC), 2018: IEEE, pp. 1-6.

[6] V. Madonna, P. Giangrande, L. Lusuardi, A. Cavallini, C. Gerada, and M. Galea, "Thermal overload and insulation aging of short duty cycle, aerospace motors," IEEE Transactions on Industrial Electronics, 2019.

[7] G. C. Montanari and L. Simoni, "Aging phenomenology and modeling," IEEE Transactions on Electrical Insulation, vol. 28, no. 5, pp. 755-776, 1993.

[8] T. W. Dakin, "Electrical insulation deterioration treated as a chemical rate phenomenon," Transactions of the American Institute of Electrical Engineers, vol. 67, no. 1, pp. 113-122, 1948.

[9] V. Montsinger, "Loading transformers by temperature," Transactions of the American Institute of Electrical Engineers, vol. 49, no. 2, pp. 776790, 1930.

[10] V. Madonna, P. Giangrande, A. Walker, and M. Galea, "On the effects of advanced end-winding cooling on the design and performance of electrical machines," in 2018 XIII International Conference on Electrical Machines (ICEM), 2018: IEEE, pp. 311-317.

[11] P. Giangrande et al., "Considerations on the Development of an Electric Drive for a Secondary Flight Control Electromechanical Actuator," IEEE Transactions on Industry Applications, vol. 55, no. 4, pp. $3544-$ 3554, 2019.

[12] S. Grubic, J. M. Aller, B. Lu, and T. G. Habetler, "A survey on testing and monitoring methods for stator insulation systems of low-voltage induction machines focusing on turn insulation problems," IEEE Transactions on Industrial Electronics, vol. 55, no. 12, pp. 4127-4136, 2008.

[13] S. A. Odhano, P. Giangrande, R. I. Bojoi, and C. Gerada, "SelfCommissioning of Interior Permanent- Magnet Synchronous Motor Drives With High-Frequency Current Injection," IEEE Transactions on Industry Applications, vol. 50, no. 5, pp. 3295-3303, 2014.

[14] ASTM-D2307, "Standard Test Method for Thermal Endurance of FilmInsulated Round Magnet Wire," 2013.

[15] I. 60172, "Test procedure for the determination of the temperature index of enamelled and tape wrapped winding wires," 2015.

[16] "IEEE Standard Test Procedure for Thermal Evaluation of Systems of Insulating Materials for Random-Wound AC Electric Machinery," IEEE Std 117-2015 (Revision of IEEE Std 117-1974), pp. 1-34, 2016.

[17] F. Burden and D. Winkler, "Bayesian regularization of neural networks," in Artificial neural networks: Springer, 2008, pp. 23-42.

[18] M. R. Khowja et al., "Novel Permanent Magnet Synchronous Motor with Integrated Filter Inductor, Using Motor's Inherent Magnetics," IEEE Transactions on Industrial Electronics, 2020, Accepted

[19] C. Sciascera, P. Giangrande, C. Brunson, M. Galea, and C. Gerada, "Optimal design of an electro-mechanical actuator for aerospace application," in IECON 2015 - 41st Annual Conference of the IEEE Industrial Electronics Society, 2015, pp. 001903-001908.

[20] V. Madonna, P. Giangrande, and M. Galea, "Evaluation of strand-tostrand capacitance and dissipation factor in thermally aged enamelled coils for low-voltage electrical machines," IET Science, Measurement \& Technology, vol. 13, no. 8, pp. 1170-1177, 2019.

[21] J.-X. Zhao, H.-Z. Jin, and H.-W. Han, "Dielectric Loss Factor Forecasting Based on Artificial Neural Network," in 2009 Second International Conference on Information and Computing Science, 2009, vol. 3: IEEE, pp. 177-180.

[22] N. Hecht, "Theory of the backpropagation neural network," in International 1989 Joint Conference on Neural Networks, 1989, pp. 593-605 vol.1.

[23] Gulrukh Turabee, Georgina Cosma, Vincenzo Madonna, Paolo Giangrande, Muhammad Raza Khowja, Gaurang Vakil, Chris Gerada, Michael Galea, "Predicting Insulation Resistance of Enamelled Wire using Neural Network and Curve Fit Methods, Under Thermal Aging," in IEEE World Congress On Computational Intelligence (WCCI), Glasgow, United Kingdom, 2020, In Press.

[24] Z. Xu et al., "Thermal management of a permanent magnet motor for an directly coupled pump," in 2016 XXII International Conference on Electrical Machines (ICEM), 2016, pp. 2738-2744.

[25] P. Giangrande, V. Madonna, S. Nuzzo, and M. Galea, "Moving Towards a Reliability-Oriented Design Approach of Low-Voltage Electrical Machines by Including Insulation Thermal Aging Considerations," IEEE Transactions on Transportation Electrification, pp. 1-1, 2020. 